\title{
Non-Descriptive Puppy and its Successful Surgical Correction
}

\author{
M. Madeena Begum* and V. Bhuvaneshwari
}

Heart2Heart Veterinary Hospital No.3, Leith Castle Center Street, Santhome, Chennai-600028

Received: 19 July, 2018; Accepted: 16 August, 2018; Published: 2 October, 2018

*Corresponding author: M. Madeena Begum, Heart2Heart Veterinary Hospital No.3, Leith Castle Center Street, Santhome, Chennai-600028, E-mail: mohammed.deena@gmail.com

\begin{abstract}
A 50 day old Non-Descriptive puppy weighing $0.9 \mathrm{~kg}$ was brought to the hospital, for evaluation of regurgitation of 6 day. The puppy began regurgitating 6 days before at the time of weaning to solid food. The puppy was thin, underweight and had distended abdomen, contrast radiograph revealed megaoesophagus and constriction of the oesophagus at the base of the heart and the condition was diagnosed as Persistent Right Aortic Arch (PRAA). Left lateral thoracotomy was performed and PRAA was surgically corrected. Long term follow-up for 6 months was conducted, pet recovered uneventfully.
\end{abstract}

Keywords: Persistent Right Aortic Arch (PRAA); Megaoesophagus; Thoracotomy

PRAA is a congenital anomaly which occurs commonly in larger breed dogs like German Shepherd and Irish Setter but rare in Non-Descriptive dogs $[1,3,4]$. Puppies with vascular ring anomaly like PRAA usually have histories of postprandial regurgitation of solid foods after weaning. In this condition the oesophagus becomes trapped by the ligament which extends from pulmonary artery and the aorta at the level of base of the heart, which leads to regurgitation of solid food and megaoesophagus in case of puppies and it can be diagnosed with the help of contrast radiography using barium swallow $[2,5,6]$.

\section{Case History and Observations}

A 50 day old Non-Descriptive puppy weighing $0.9 \mathrm{~kg}$ was brought to the hospital, for continues regurgitation of solid foods for past 6 day from the time of weaning to solid food. On physical examination puppy was thin, underweight and had distended abdomen, contrast radiograph revealed megaoesophagus and constriction of the oesophagus at the base of the heart (Figure 1) and the condition was diagnosed as persistent right aortic arch and surgery was fixed[5,6].

\section{Treatment and Discussion}

Puppy was pre-anesthetized with diazepam at the dose rate of $0.25 \mathrm{mg} / \mathrm{kg}$ body weight and butorphanol tartrate 3 at the dose rate of $0.1 \mathrm{mg} / \mathrm{kg}$ body weight intravenously and then pre-oxygenated with a mask for 5 minutes. Induction of anaesthesia was done with 4 per cent Isoflurane in oxygen by mask induction technique and intubation of the trachea was

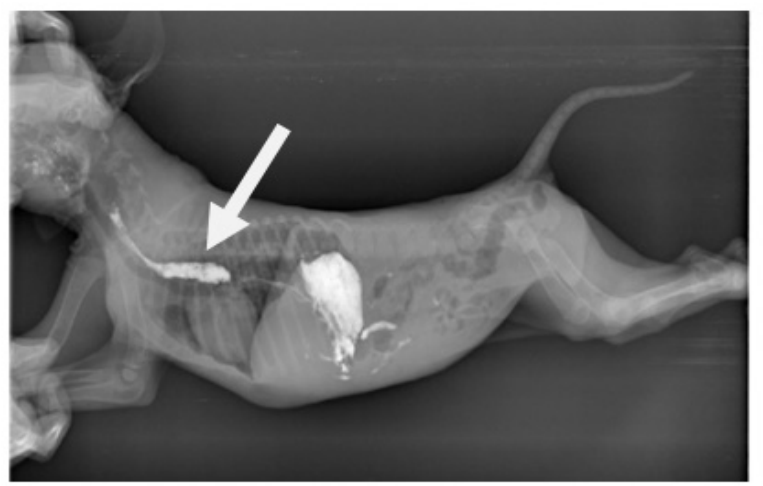

Figure 1: Pre-operative contrast radiograph shows megaoesophagus which constrict at the level of base of the heart

done with the cuffed endotracheal tube size $4.5 \mathrm{~mm}$, which was connected to a anaesthesia machine by Bain's circuit. Anesthesia was maintained with 2-3 per cent Isoflurane in oxygen. Puppy was mechanically ventilated ( 20 breaths/min) using intermittent positive pressure ventilation and left lateral thoracotomy was performed by making incision on fourth intercostals space and a retractor was fixed between 4th and 5th rib [7]. The phrenic, vagus and recurrent laryngeal nerves were indentified and protected then the ligamentum arteriosum which constricting the oesophagus was identified and isolated by dissection (Figure 2 ). The constricting band was cut and released after placing two sutures, $1 \mathrm{~cm}$ apart each other with 3-0 non absorbable suture material [Figure 3]. The fibrous tissue on the constricted site of esophagus was dissected off. A foley's catheter was inserted in to the esophagus and additional constriction was ruled out. Rib cage was closed with Poly Glycolic Acid No.1 by interrupted cricumcostal sutures. Elimination of pneumothorax and reestablishment of negative intrathoracic pressure was achieved by inflation and expansion of lung by compressing reservoir bag, just before suturing the final suture. Subcutaneous tissue sutured using Poly Glycolic Acid No.2-0 and skin apposed using Polyamide No. 3-0. Postoperatively, puppy was maintained with intravenous cephalosporin (Intacef Tazo) at the dose rate of $22 \mathrm{mg} / \mathrm{kg}$ body weight for one week, intravenous fluid therapy for 48 hours and elevated feed was carried for first two weeks, wound dressing 


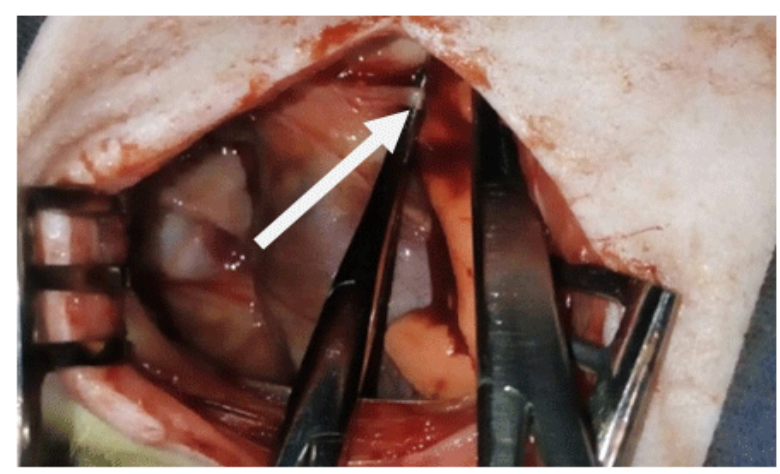

Figure 2: Intra-operative picture shows persistent ligamentum arteriosum

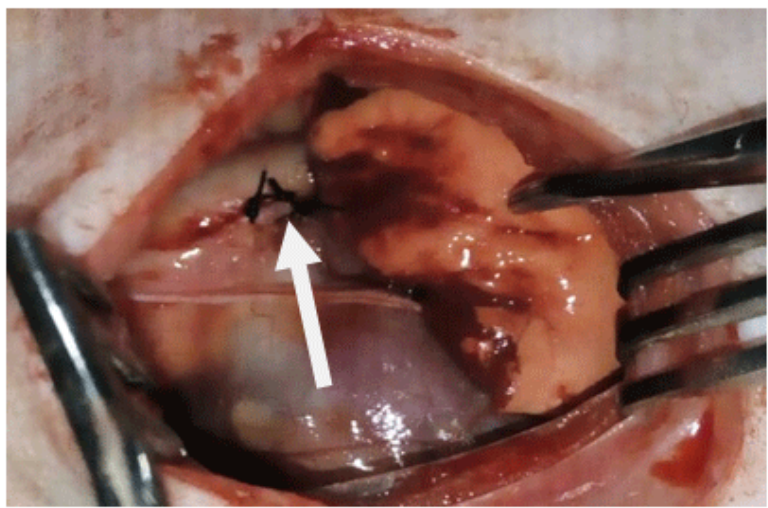

Figure 3: Intra-operative picture shows double suturing of ligamentum arteriosum

with antibiotic ointment were continued for up to 10 days. Skin suture was removed after healing on 10th postoperative day. A long term follow-up of six month revealed complete recovery of the pet happened within a month and no complications were noticed even after six month of the surgery. Successful post operative recovery is mainly due to the earlier diagnosis and surgical correction which is generally recommended to minimize permanent dilation of the esophagus due to loss of neuromuscular function and peristalsis of the esophagus $[7,8,9]$. Surgical treatment is the best option whereas most of the medical treatment of PRAA cases where unsuccessful with a poor longterm prognosis $[5,6,8]$.

\section{Summary}

Persistent Right Aortic Arch was successfully corrected by surgery and no complications were evident under long term follow-up.

\section{References}

1. Ashrafian H, Tsang V, Kostolny M. Rare presentation of subclavian artery isolation in a neonate with a family history of aortic arch anomalies. Ann Thorac Surg. 2007;83(6):2226-2228. DOI: 10.1016/j. athoracsur.2006.11.037

2. Bottorff B, Sisson D. Hypoplastic aberrant left subclavian artery in a dog with a persistent right aortic arch. J Vet Cardiol. 2012;14(2):381-385. DOI: 10.1016/j.jvc.2012.01.013

3. Christiansen KJ, Snyder D, Buchanan JW, Holt DE. Multiple vascular anomalies in a regurgitating german shepherd puppy. J Small Anim Pract. 2007;48(1):32-35.

4. Du Plessis C J, Keller N, Joubert KE. Symmetrical Double Aortic Arch in a Beagle Puppy. J Small Anim Pract. 2006;47(1):31-34.

5. Harari J. Small Animal Surgery. William and Wilkins. Pennsylvania. 1996;127-128.

6. Jung J, Cho Y, Jung Y, Jeong J, Lee K. Diagnosis and treatment of an aberrant right subclavian artery with persistent right ligamentum arteriosum in a kitten. Pak Vet J. 2015;35(1):119-122.

7. Jurado 0 M, Mosing M, Bettschart-Wolfensberger R. Anaesthetic management of a 1-month-old puppy undergoing lateral thoracotomy for vascular ring anomaly correction. Case Reports. Vet Med. 2011;16.

8. Koc Y, Turgut K, Sen I, Alkan F, Birdane MF. Persistent Right Aortic Arch and its Surgical Correction in a Dog. Turk. J Vet Anim Sci. 2004;28:441446.

9. Plesman R, Johnson M, Rurak S, Ambrose B, Shmon C. Thoracoscopic correction of a congenital persistent right aortic arch in a young cat. Can Vet J. 2011;52(10):1123-1128. 